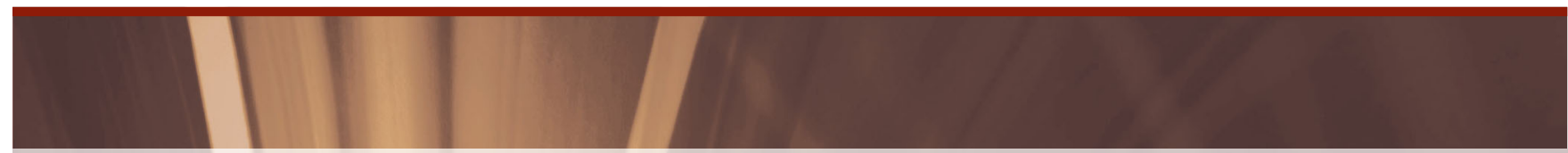

\title{
A Celebration of Excellence: 2019 TMS Society Awards
}

\section{Ashley-Anne Bohnert and Carol Matty}

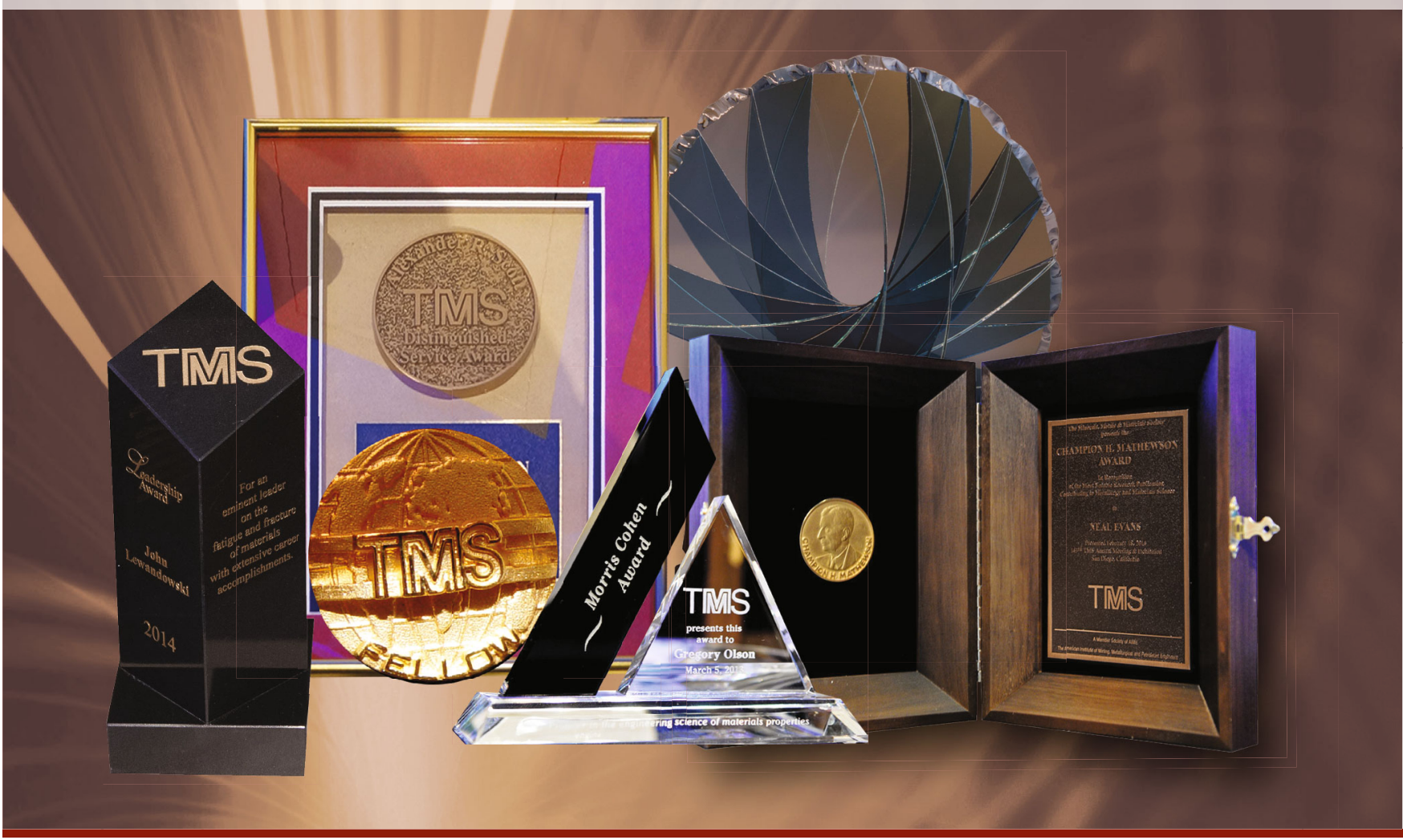

TMS awards are prestigious acknowledgements of a recipient's lasting contribution to the fields of minerals, metals, and materials science and engineering. Many of these awards celebrate distinguished service to the Society and to the professional community by highlighting scholarly, leadership, or mentoring accomplishments that elevate the field and inspire future generations.

The awards presented in this article will be conferred during the TMS-AIME Awards Ceremony, scheduled for Wednesday March 13, 2019, as part of the TMS 2019 Annual Meeting \& Exhibition (TMS2019), held from March 10-14, in San Antonio, Texas. Receiving a TMS award is considered a significant milestone in any career, so the ceremony is open to TMS2019 attendees who wish to join in celebrating the accomplishments of their colleagues.

\section{NOMINATE A GOLLEAGUE BY APRIL 1}

Nominations are now being accepted for 2020 TMS awards. Acknowledge the accomplishments of a distinguished colleague by submitting a nomination packet before the deadline of April 1, 2019.

To begin the nomination process or to see a complete list of awards, criteria, and instructions, visit the TMS Honors and Awards website at awards.tms.org. For additional information, contact Deborah Hixon, TMS Awards Program Administrator, at awards@tms.org. 


\section{SOCIETY AWARDS}

\section{TMS FELLOWS}

The class of Fellow is TMS's highest honor. To be inducted, a candidate must be recognized as a leading authority and contributor to the practice of metallurgy, materials science, and technology, with strong consideration given for outstanding service to the Society.

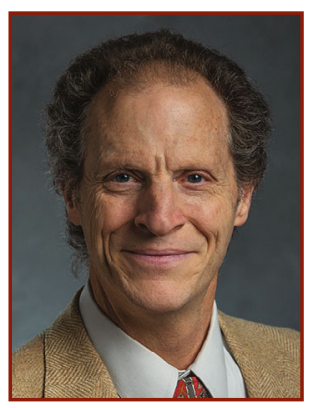

\section{Thomas Bieler, Professor and} Director, Michigan State University

Citation: For seminal scientific and technological contributions to the understanding of the influence of grain boundaries and texture on the processing and properties of engineering alloys.

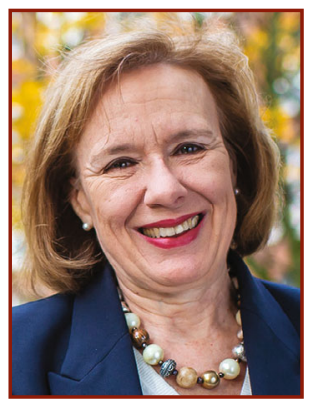

M. Grace Burke, Professor and Director, University of Manchester Citation: For extraordinary experimental skills in determining the causes of brittle failure and stress corrosion cracking in nuclear reactor materials.

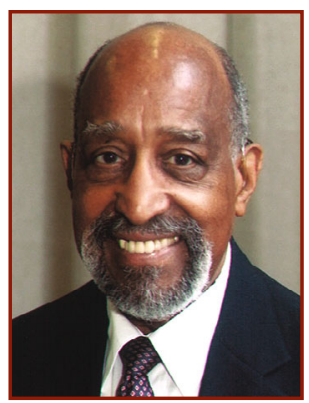

Frank Crossley, Retired, Aerojet Propulsion Research Institute Citation: For the pioneering development and application of titanium alloys into crucial aerospace applications, both commercial and defense, including critical U.S. national security areas.

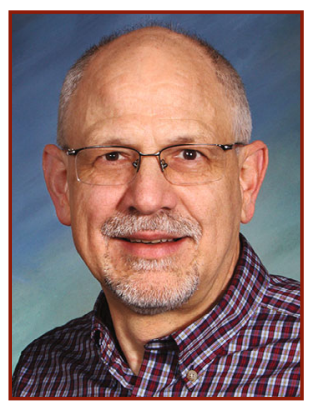

\section{Dennis Dimiduk, Chief}

Technologist, BlueQuartz Software LLC

Citation: For leadership and contributions to high-temperature and intermetallic materials development, integrated materials modeling, 3D materials science, and the science of size-scale effects in plasticity.

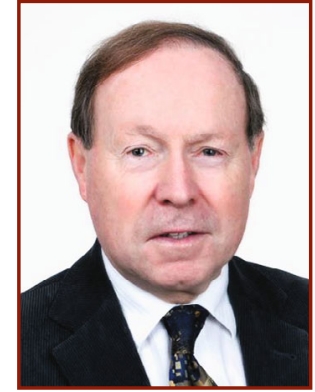

Roderick Guthrie, Director of McGill Metals Processing Centre, McGill University

Citation: In recognition of his outstanding research contributions to the development of ferrous and nonferrous processes, and a distinguished academic career in the education of students.

"I have a deep respect for TMS," Guthrie stated. "Having been a TMS member since 1969, I have had the opportunity to present many of my, and my students', research contributions. Meantime, I have watched the TMS organization grow into a global force for good. Given the many active members and contributors from all around the world, I am hopeful that this will continue. As such, I accept this recognition of being named a Fellow of TMS with gratitude and pride."

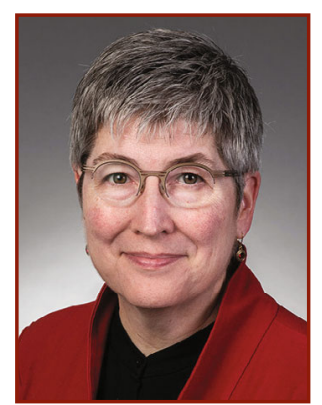

Elizabeth Holm, Professor, Carnegie Mellon University Citation: For pioneering achievements and leadership in computational materials science and integrated computational materials engineering and for distinguished service to the materials profession.

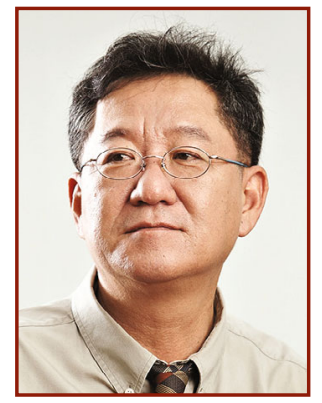

Nack Joon Kim, Professor, Pohang University of Science and Technology

Citation: For seminal contributions toward the development of high performance structural alloys through microstructure design, leading to commercialization of these alloys in various applications.

"I joined TMS as a graduate student in the United States and it has been one of my principal professional societies throughout my career, although I have been conducting research in Korea for some 30 years," Kim said. "As a long-time international member, I am deeply honored to be recognized by TMS and would like to share this honor with my colleagues, postdocs, and students, without whose support this prestigious award would not have been possible." 


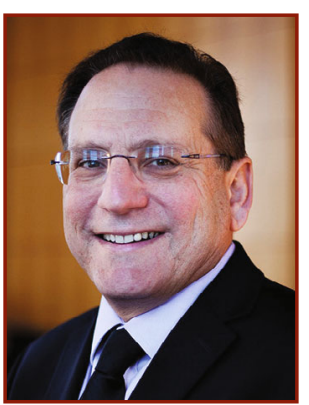

Alan Taub, Professor, University of Michigan

Citation: For advancing materials technology and commercialization through a combination of personal research accomplishments and technology leadership in both industry and academia.

"I first joined TMS as a graduate student and have relied on the meetings and publications to learn about the latest developments in my field," Taub noted. "As a Society that embraces the intersection of science and engineering, TMS enables me to interact with a broad range of researchers from industry, national laboratories, and academia from around the world. It is quite an honor to be recognized as a Fellow by this community."

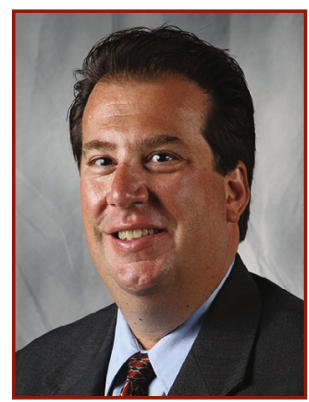

Dan Thoma, Director, Grainger Institute for Engineering, University of Wisconsin-Madison Citation: For pioneering research in advanced processing and alloy design as well as for leadership of and service to the materials profession.

"Receiving the prestigious TMS Fellow Award is a humbling honor," expressed Thoma. "TMS is my primary source for professional information dissemination and networking. Since I was a student, I have admired the leadership and the contributions of past TMS Fellows. To be recognized within this esteemed group is truly rewarding. I look forward to future years of continued, productive interactions and service."

\section{BRIMACOMBE MEDALISTS}

This mid-career award recognizes individuals with sustained excellence and achievement in business, technology, education, public policy, or science related to minerals, metals, or materials science and engineering, and a record of continuing service to the profession.

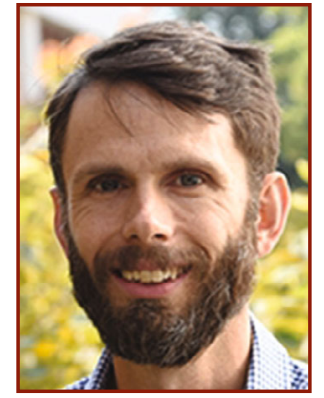

Sean Agnew, Director of Engineering Science Major, University of Virginia Citation: For outstanding contributions to advancing the scientific understanding of deformation mechanisms and the associated mechanical response of magnesium-based and other metals.

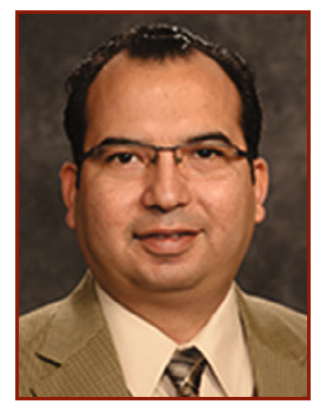

Raymundo Arroyave, Professor, Texas A\&M University Citation: For his leadership in integrating informatics and data science into materials design and for exemplary service to the materials community through his dedication to TMS.

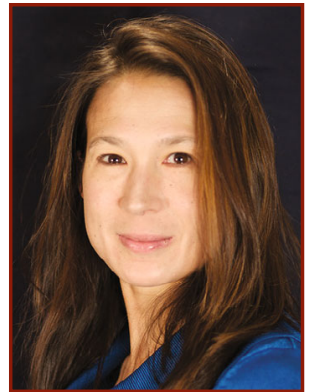

Irene Beyerlein, Professor, University of California, Santa Barbara

Citation: For groundbreaking work on the plasticity of $\mathrm{HCP}$ metals and metal nanocomposites as well as for her commitment to mentorship of the next generation of materials scientists.

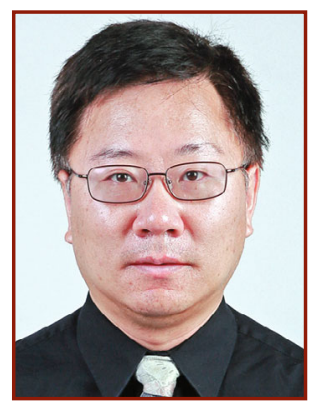

Jian Luo, Professor, University of California, San Diego

Citation: For significant contributions of understanding materials interfaces, especially developing grain boundary phase diagrams and uncovering the mysterious mechanisms of liquid metal embrittlement and activated sintering

"I am truly honored to receive a TMS Brimacombe Medal," Luo said. "Trained as a ceramist, I am currently working almost equally on metals and ceramics, with a focus on interfaces. TMS offers a wonderful interdisciplinary scientific discussion platform across different types of materials. Participating in technical committees and co-organizing symposia are also highly fruitful experiences for me, and TMS is instrumental in helping my career and professional development." 


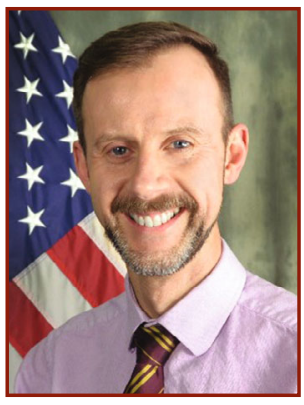

Jonathan Spowart, Senior Materials Research Engineer, United States Air Force Citation: In recognition of outstanding contributions to the field of materials characterization which have enabled numerous advances in materials science and engineering.

"TMS membership has provided me with unparalleled benefits over a multi-decade career in the materials science profession," noted Spowart. "I have been an active member of TMS for over 25 years and, as my career has progressed, TMS has been there every step of the way. TMS membership has allowed me to grow substantially and professionally over that time, and has allowed me to make a difference in the lives of others. TMS membership provides a platform and foundation for personal and professional excellence, and has truly enabled me to accomplish those things that the Brimacombe Medal celebrates and recognizes in its recipients. I am extremely happy and genuinely humbled by this prestigious award, and I look forward to serving TMS for many years to come."

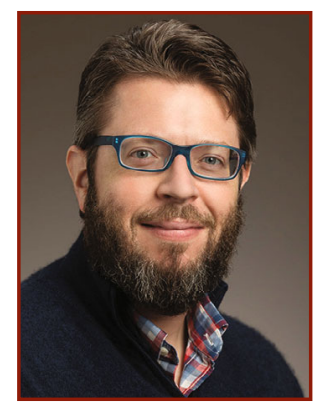

Dallas Trinkle, Associate

Professor, University of Illinois at

Urbana-Champaign

Citation: For significant

contributions to the prediction of alloying efforts on diffusion, solid solution strengthening and softening and for exemplary service to TMS.

"I am honored to receive this award from TMS. TMS has been my home professional Society for fifteen years," said Trinkle. "I have had many opportunities to present new and exciting results for myself at first and now for my research group. As a 'bottom-up' organization, I have enjoyed working with my colleagues in the science and engineering community to develop programming and work for the community. I am honored to receive this recognition from my colleagues, and humbled to join the ranks of Brimacombe Medalist awardees."

\section{ALEXANDER SCOTT DISTINGUISHED SERVICE AWARD}

Recognizing a member's outstanding contributions to TMS, this award is typically presented for 10 or more years of TMS service in membership development, student chapters, education and professional affairs, and/or other Society level activity.

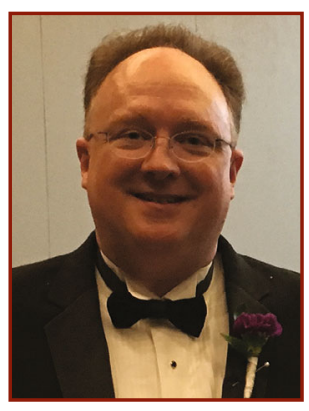

Robert Hyers, Professor, University of Massachusetts Citation: For more than a decade of selfless and dedicated service, and exceptional leadership to TMS through the organizing of symposia, committee memberships, Financial Planning Officer, and membership of the Executive Committee and Board of Directors.

"TMS is my main professional home," Hyers stated. "TMS is where I learned how to participate in a professional society. Volunteering for TMS gave me opportunities to meet most of the colleagues in my professional network, something to do with them so that we could build acquaintances into professional relationships, and once in a while, a chance to make a difference."

\section{JULIA AND JOHANNES WEERTMAN EDUCATOR AWARD}

This award recognizes an individual who has made outstanding contributions to education in metallurgical engineering and/or materials science and engineering.

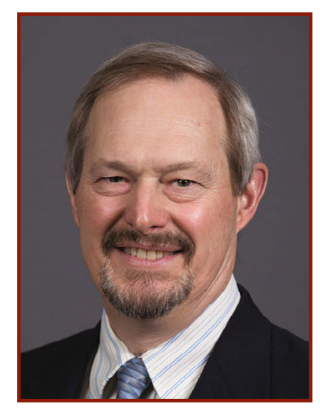

David Van Aken, Professor, Missouri University of Science and Technology

Citation: For more than three decades of exemplary education of students in physical metallurgy and the development of innovative technologies to produce next generation high strength steels. 


\section{LEADERSHIP AWARD}

This award recognizes an individual who has demonstrated outstanding leadership in the national and international materials community.

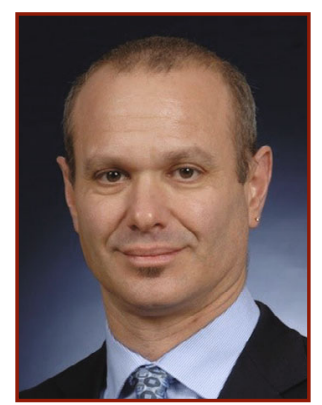

James Warren, Director, Materials Genome Program, National Institute of Standards and Technology

Citation: For exceptional leadership in realizing the vision of the Materials Genome Initiative (MGI) to discover, manufacture, and deploy advanced materials twice as fast, at a fraction of the cost.

"This award from my TMS colleagues is very meaningful," stated Warren. "TMS has been one of the most forwardlooking organizations in support of the mission of the Materials Genome Initiative, acting as a true partner in realizing the vision to accelerate materials discovery. Having devoted the last nine years of my career to this goal, having TMS in my corner has made an enormous difference. I believe that my leadership was buoyed by the leadership TMS has shown."

\section{APPLICATION TO PRACTICE AWARD}

This award recognizes an individual who has demonstrated outstanding achievement in transferring research results or findings into commercial production and practical use.

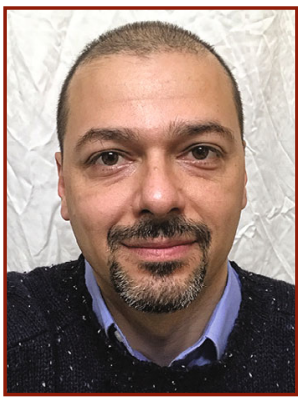

Don Lipkin, Senior Principal Scientist, GE Global Research Citation: For outstanding contributions to the application of materials science to gas turbine technology, especially on protective coatings that enable benefits in efficiency and environmental impact.

\section{BRUCE CHALMERS AWARD}

Honors outstanding contributions to the science and/or technology of materials processing by an individual.

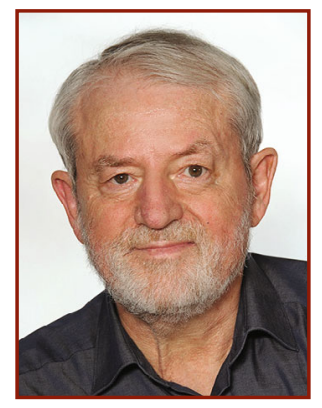

\section{MORRIS COHEN AWARD}

Recognizes an individual who has made outstanding contributions to the science and/or technology of materials properties.

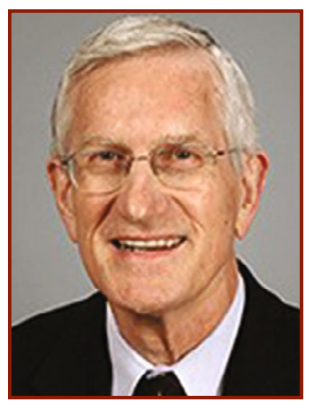

William Gerberich, Professor Emeritus, University of Minnesota Citation: For developing mechanistic relationships between the structure and mechanical properties of materials. Gerberich reflected: "I can reminisce upon several outstanding events during my career: the ability to give a pre-doc lecture at California Institute of Technology; an invitation from Max Williams to be editor of International Journal of Fracture; giving an American Association for the Advancement of Science contribution in 1968; attending TMS departmental receptions in the 1990s; and finally, being part of an honorary session at the TMS 2006 Annual Meeting \& Exhibition. Above all, my fondest reminiscence is from last year's retirement of my best students calling me 'Mr. Sunshine' for encouraging excellence in materials science.'

\section{OLEG D. SHERBY AWARD}

This award recognizes an individual, or small group of collaborators, who has made significant contributions to the understanding of the behavior of materials at high temperatures.

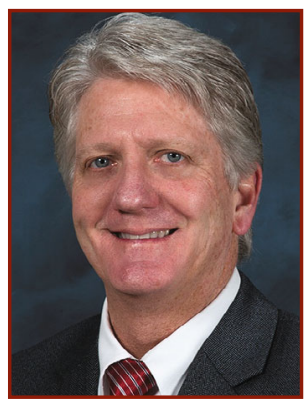

Michael Mills, Professor, The Ohio State University Citation: For understanding creep behavior in complex metallic alloys using advanced characterization methods to gain new insights into deformation mechanisms and develop new models of deformation.

\section{WILLIAM HUME-ROTHERY AWARD}

Awarded in recognition of exceptional scholarly contributions to the science of alloys.

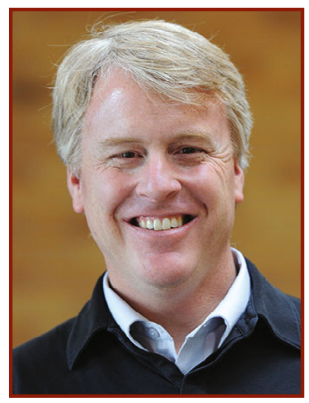

Mark Asta, Professor, University of California, Berkeley Citation: For his foundational contributions to the theory and simulation of the thermodynamic and kinetic behavior of bulk and interfacial inorganic alloys. 
INSTITUTE OF METALS LECTURER \& ROBERT FRANKLIN MEHL AWARD

In receiving this pinnacle award, honorees present a lecture at the TMS Annual Meeting \& Exhibition, which is also published in Metallurgical and Materials Transactions A.

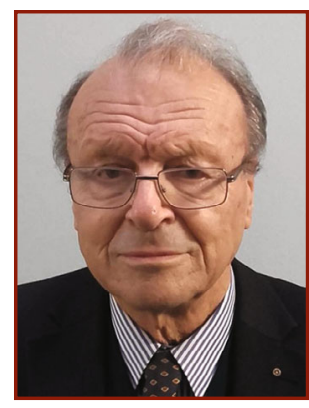

Hael Mughrabi, Professor

Emeritus, University of

Erlangen-Nürnberg

Citation: For seminal discoveries

that had a profound effect on

our understanding of plastic

deformation and failure of metals

with particular emphasis on fatigue

and for global leadership.

"During the past nearly 35 years

of my membership with TMS, I have repeatedly attended TMS meetings where I have given talks and enjoyed valuable scientific and personal connections with many other colleagues," Mughrabi said. "Over the years, I have witnessed how TMS has expanded its influence internationally. In this way, TMS has become an essential part of my professional and scientific activities. I consider the receipt of this prestigious TMS award a very special recognition of the work of my research group, and I am very proud to be honored in this way."

\section{ELLEN SWALLOW RICHARDS DIVERSITY AWARD}

Honors the contributions of an individual who reflects the pioneering spirit of Ellen Swallow Richards in overcoming personal, professional, educational, cultural, or institutional adversity to pursue a career in the minerals, metals, and/ or materials professions or in helping others in the field to overcome similar challenges.

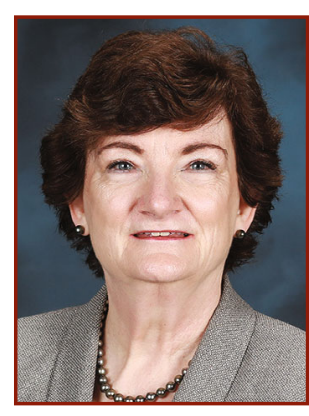

Michelle Buchanan, Deputy for Science \& Technology, Oak Ridge National Laboratory

Citation: For her efforts to increase diversity in hiring, exceptional mentoring, and advocacy for early career scientists, and tireless dedication to improving workplace culture.

"TMS membership and the TMS Foundation benefit me through broad communication of recent advances in materials research, both within the community and to the general public," Buchanan noted.

\section{FRANK CROSSLEY DIVERSITY AWARD}

Honors an individual who has personally overcome personal, professional, educational, cultural, or institutional adversity to pursue a career in minerals, metals, and/or materials.

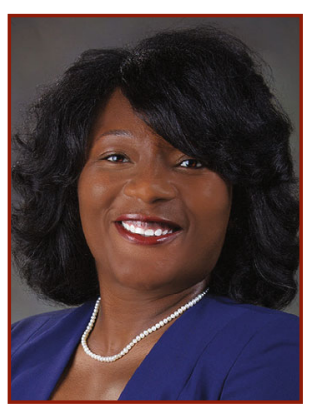

\section{Olivia Underwood, Product Realization Team Leader, Sandia National Laboratories} Citation: For a first generation college graduate; exemplifying persistence in her academic degree; a professional career leader; and outreach to underrepresented women in STEM. "TMS membership and the TMS Foundation benefit me by providing me a platform to share my latest work with the research community along with the opportunity to be able to attend the different talks and workshops of others when attending the TMS conferences," Underwood stated. "It allows me to network and collaborate with others. It also allows me to stay connected to my colleagues. Last but not least, it is great to have access to the free journals and to be able to serve on different committees."

\section{EARLY CAREER FACULTY FELLOWS}

This award recognizes an assistant professor for his or her accomplishments that have advanced the academic institution where employed, and for abilities to broaden the technological profile of TMS.

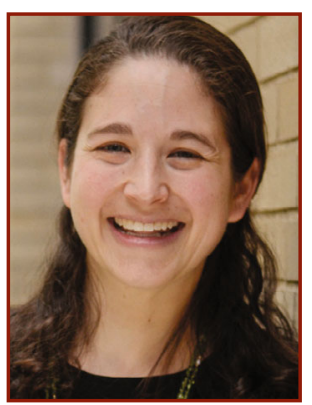

Elsa Olivetti, Assistant Professor, Massachusetts Institute of Technology Lecture: "Data Mining to Guide Synthesis Towards ResourceEffective Materials, Processes and Systems"

"TMS membership provides me with the opportunity to connect with colleagues from a range of organizations and backgrounds on topics I'm interested in and am working on," Olivetti observed. "I'm grateful for the opportunity that TMS membership provides me with to build these networks, present my work and the work of my students for feedback, as well as identify new research opportunities and collaborations. TMS membership also provides me with an opportunity to connect my academic work with industry members or move research in a direction that is more valuable to industry. Finally, I'm able to learn about recent critical advances in the field." 


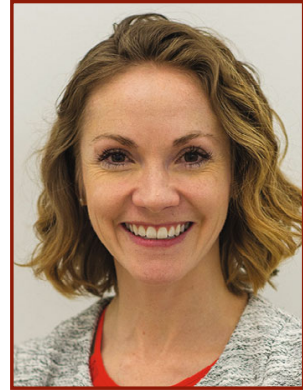

Ashley Spear, Assistant Professor, University of Utah

Lecture: "Data-Driven Materials Science: Successes, Challenges, and Opportunities"

"I first joined TMS as a graduate student in 2011. At that time, I was able to start developing a network by attending and presenting at the TMS Annual Meeting," Spear noted. "I would always look forward to learning about the latest research in the community and meeting new people. Once I became a faculty member, my network within TMS expanded. I am pleased to say that my students are now active in the TMS community and have been presenting their research at the annual meeting for the last few years. I feel extremely fortunate to have found a strong and supportive community in TMS."

\section{TMS BEST PAPER CONTEST}

This award recognizes student essays on global or national issues as well as technical research papers, relating to any field of metallurgy or materials science.

\section{Graduate-1st Place}

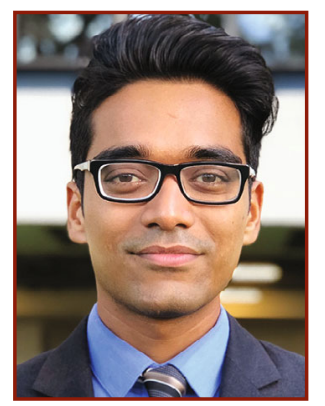

Pranjal Nautiyal, Student, Florida International University

"I started my Ph.D. in materials engineering in 2015 and have been a Material Advantage (MA) member since then," Nautiyal stated. "I have participated in student contests, received TMS travel grants to attend conferences, and interacted with other fellow students and researchers in the materials community. I also chaired the MA chapter in my university, which has helped me to gain leadership experience, engage in social outreach, and get to know successful professionals in my area. TMS has helped me develop skill sets that will be helpful for me to succeed."

\section{Graduate-2nd Place}

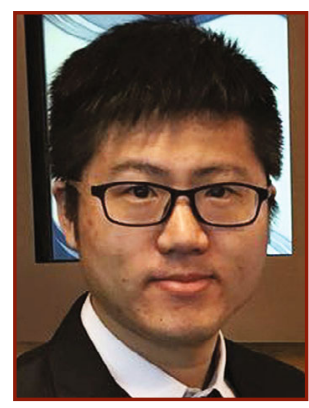

Rui Feng, Student, University of Tennessee, Knoxville

"It is my great honor to receive this award again," noted Feng. "I would like to thank the TMS Foundation and Material Advantage, which offer me a wealth of resources to connect with many excellent researchers and stay up to date with the cutting-edge progress in my field. With the stimulation from this award, I will continue my hard work and passion in my future academic research and any other engaged works."

\section{AIME AWARDS}

\section{AIME HONORARY MEMBERSHIP}

Conferred upon an individual for outstanding service to or distinguished scientific or engineering achievement in the fields embracing the activities of the American Institute of Mining, Metallurgical, and Petroleum Engineers (AIME) and its member societies.

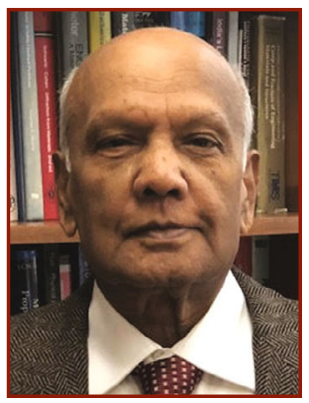

K. Linga Murty, Professor, North Carolina State University Citation: For his contributions to the materials community through exemplary research and service in nuclear materials, high temperature deformation behavior, and nanostructured materials.

\section{TMS/SME/AIME JAMES DOUGLAS GOLD MEDAL}

Honors distinguished achievement in nonferrous metallurgy, including both the benefication of ores and the alloying and utilization of nonferrous metals. This award is administered through TMS's Extraction \& Processing Division (EPD) and the Society for Mining, Metallurgy \& Exploration's Minerals \& Metallurgical Processing Division (MPD).

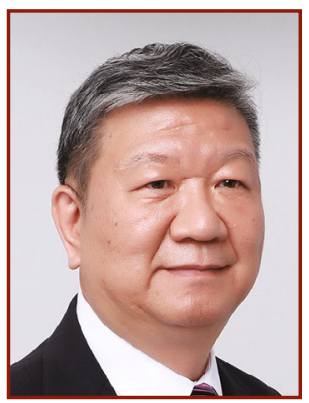

Jiann-Yang (Jim) Hwang, Professor, Michigan Technological University

Citation: For creative and exceptional contributions and leadership for the mineral processing and metallurgy community for over 40 years. 


\section{AIME ROBERT LANSING HARDY AWARDS}

For more than half a century, this award has recognized professionals under the age of 35 in the broad fields of metallurgy and materials science for exceptional promise of a successful career.

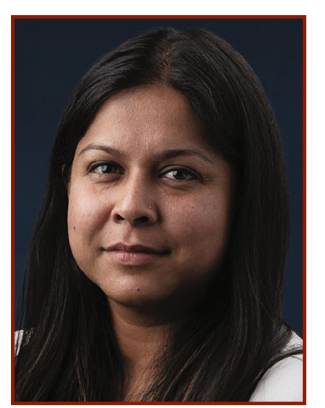

Saryu Fensin, Scientist, Los Alamos National Laboratory Citation: For innovative and scientifically groundbreaking modeling research quantifying the role of grain boundary structure on the dynamic mechanical response of materials.

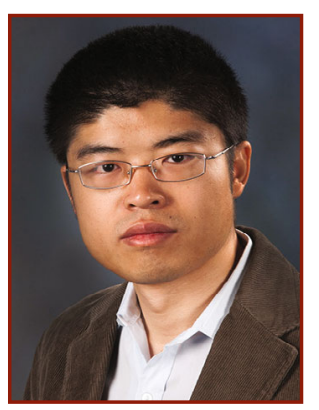

Nan Li, Staff Scientist, Los Alamos National Laboratory Citation: For elucidating the deformation mechanisms and irradiation response of nano-metals via in situ TEM nanomechanics. "I am truly honored to receive the prestigious AIME Robert Lansing Hardy Award," Li stated. "I would like to thank my nominators, my advisor and mentors, my collaborators, the members of the TMS Award Committee, and TMS Foundation for their support. This is a significant milestone in my professional career. TMS is an exciting professional society, and every time I attend the TMS Annual Meeting \& Exhibition, I am inspired by the science and networking opportunities there. I look forward to my continued contributions to this society."

\section{AIME CHAMPION H. MATHEWSON AWARDS}

Awarded to the author(s) of a paper, or a series of closely related papers, representing the most notable contribution
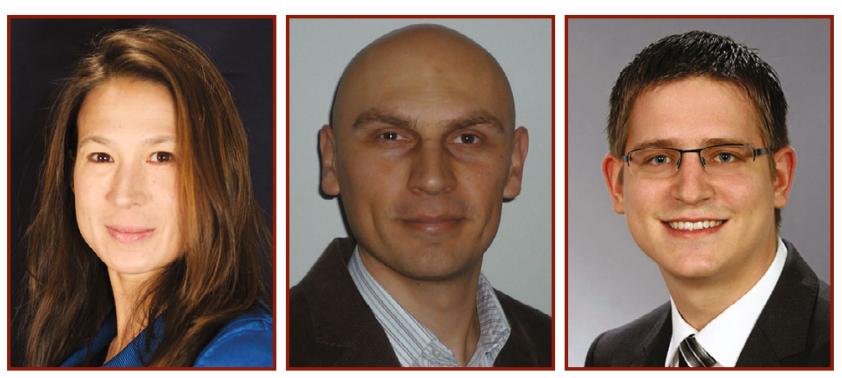

to metallurgical science during the period under review.

Pictured, left to right, are: Irene Beyerlein, Professor, University of California, Santa Barbara; Marko Knezevic, Associate Professor, University of New Hampshire; and Marcel Risse, BSH Home Appliances Corporation. Not pictured are: Christoph Fahrenson, Technical Staff Member, Technical University of Berlin; Martin Lentz, Project Manager, Hydro Aluminum Rolled Products GmbH; and Walter Reimers, Professor, Technical University of Berlin.

Paper, Light Metals Topic Area: "Elevated Temperature Effects on the Plastic Anisotropy of an Extruded Mg-4 Wt Pct Li Alloy: Experiments and Polycrystal Modeling," Metallurgical and Materials Transactions A, Vol. 48, January 2017.

"I feel very honored to be a recipient of this award. It is a strong motivator for further technical projects in the field of metallurgical and material science." Risse observed. Knezevic added, "Research efforts and accomplishments being recognized and rewarded by the TMS community always positively influence the professional development of its members. This award is a motivation for me to continue the good work and remain within the network of 

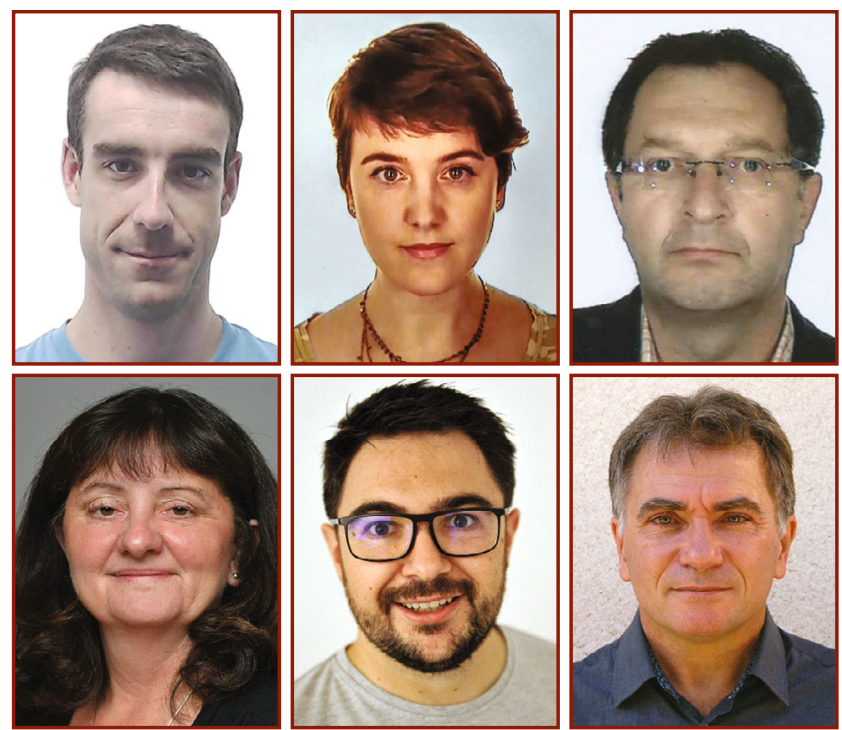

TMS members."

Pictured, left to right (top row), are: Jonathan Cormier, Associate Professor, ISAE-ENSMA and Institut Pprime; Ana Casanova Gomez, Student, University of Cambridge; Jean-Michel Franchet, Materials \& Processes Engineer, Safran Tech; (bottom row) Tresa Pollock, Professor, University of California, Santa Barbara; Damien Texier, CNRS Researcher, Institut Clement Ader, UMR CNRS; and Patrick Villechaise, Senior Researcher, Institut Pprime-CNRS. Not pictured is: Stephane Pierret,
Engineer, Safran Aircraft Engines.

Paper, Mechanical Behavior Topic Area: "Microstructural Features Controlling the Variability in Low-Cycle Fatigue Properties of Alloy Inconel 718DA at Intermediate Temperature," Metallurgical and Materials Transactions A, Vol. 47, March 2016.

"This award is a great honor that recognizes starting research activities with colleagues I particularly appreciate," noted Texier. Gomez added, "I am very honored to share this award with a team of great professionals that I deeply admire." Franchet noted, "This award recognizes a long-term collaboration on metallurgical and mechanical studies concerning high strength disk superalloys for rotating components in gas turbines." Villechaise added, "This is a nice recognition for an experimental study developed in collaboration between these research teams." Cormier noted, "TMS allowed me to network with colleagues all around the world and for me, TMS is the leading organization for dissemination of scientific knowledge through its journals and conferences."

\section{AIME HENRY DEWITT SMITH SCHOLARSHIPS}

Funded by AIME, of which TMS is a member society, this scholarship is awarded to graduate students majoring in mineral, metals, and/or materials engineering. The AIME Henry DeWitt Smith Scholarship aims to advance the mineral industries by assisting students in the pursuit of graduate education in mining, metallurgical, materials, or petroleum-related disciplines.

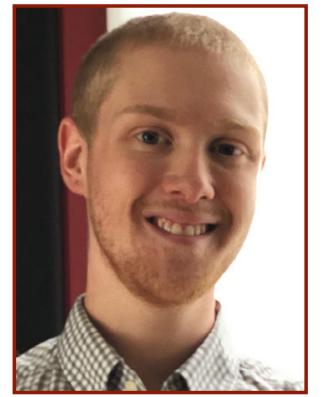
the opportunity to share my research with a broader audience at TMS conferences. I have also been afforded opportunities to conduct research on multiple projects that aren't directly related to my Ph.D. research as a result of attendance at MA meetings. This extra experience not only improved my confidence and competence in the techniques required to conduct my research, but has also helped me determine which career path I wish to take.

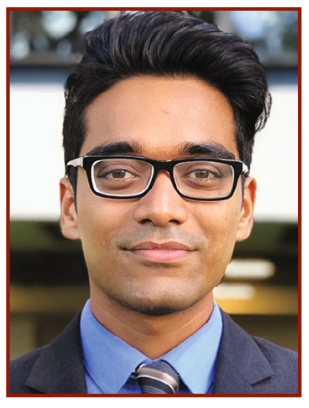

Pranjal Nautiyal, Student, Florida International University "I started my Ph.D. in materials engineering in 2015 and have been a Material Advantage (MA) member since then," Nautiyal stated. "I have participated in student contests, received TMS travel grants to attend conferences, and interacted with other fellow students and researchers in the materials community. I also chaired the MA chapter in my university, which has helped me to gain leadership experience, engage in social outreach, and get to know successful professionals in my area. TMS has helped me develop skill sets that will be helpful for me to succeed." 


\section{ACTA MATERIALIA AWARDS}

\section{ACTA MATERIALIA GOLD MEDAL AWARD}

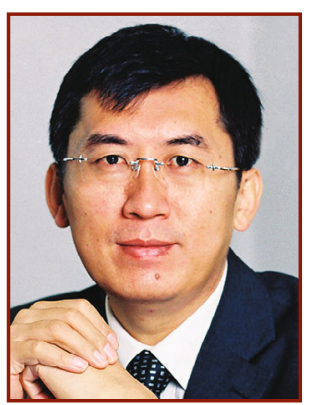

Awarded to a proven leader in materials science and engineering whose research has significantly impacted the development of the discipline.

Ke Lu, Professor and Director, Institute of Metal Research

\section{ACTA MATERIALIA SILVER MEDAL AWARD}

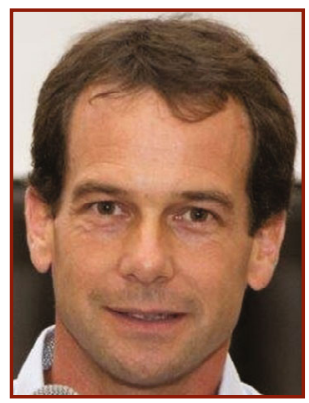

This award honors scientific contributions and leadership from academic, industry and public sector leaders in the midst of their careers.

Xavier Savage, Deputy Director, CNRS - GPM - University Rouen Normandy

\section{ACTA MATERIALIA HOLLOMAN MATERIALS \& SOCIETY AWARD}

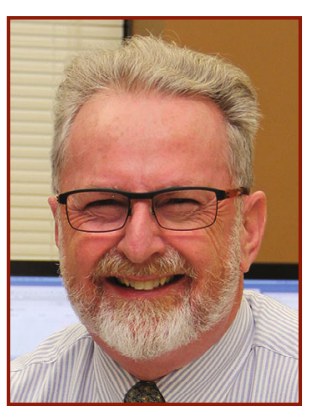

This recognition honors an individual who promotes understanding of the relationship and interactions between materials technology and societal interest or needs.

Alexander H. King, Professor, Iowa State University

\section{BRIMACOMBE PRIZE}

The Brimacombe Prize recognizes an excellent researcher, visionary, and innovator for a better society, teacher, and world ambassador, creatively integrating science and technology. The Brimacombe Prize is supported by the Brimacombe Fund, an endowment held by the Vancouver Foundation.

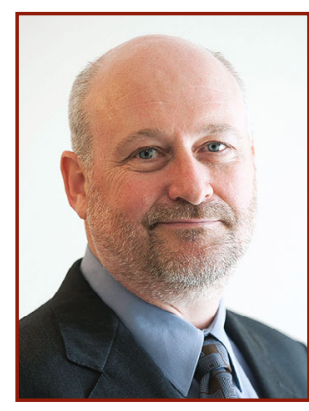

John Grandfield, Director, Grandfield Technology Pty Ltd. Citation: For outstanding achievements in materials process engineering, including being an excellent researcher who creates new and practical insights, a visionary for a better global society, innovator, teacher, and world ambassador, creatively integrating science and technology.

\section{TMS DIVISION AWARDS}

Look to the March issue of JOM to view the recipients of the many awards administered by the Society's five technical divisions: Extraction \& Processing (EPD), Functional Materials (FMD), Light Metals (LMD), Materials Processing \& Manufacturing (MPMD), and Structural Materials (SMD).

TMS Division Awards laud outstanding accomplishments within a particular realm of technical expertise, and acknowledge noteworthy service to the division and the members it represents. To learn more about these awards or to view a list of past recipients, visit the TMS Honors \& Awards home page at awards.tms.org. While there, you will also be able to learn more about the criteria and nomination process for each award.

Meaningful professional recognition is an important tool for acknowledging the achievements of our peers and for inspiring further advancements within our fields. Please consider advancing a deserving colleague by submitting a nomination packet before the April 1, 2019 deadline. 